\title{
A argumentação no gênero monografia: uma análise na perspectiva da Linguística de Texto
}

\author{
Márcia Helena de Melo Pereira* \\ Jaqueline Feitoza Santos**
}

\section{Resumo}

Neste artigo, aborda-se aspectos comunicacionais da sociorretórica e mecanismos ligados à textualidade denominados operadores argumentativos, no gênero monografia. Observa-se em que medida esses elementos auxiliam o escrevente a posicionar-se argumentativamente. Para a execução dessa investigação, coleta-se uma monografia da área de Ciências Humanas, do curso de Comunicação Social, e utiliza-se uma metodologia qualitativa, com base em pressupostos teóricos da Linguística Textual. As análises revelam a execução de movimentos sociorretóricos pelo escrevente e que os operadores argumentativos foram responsáveis pelo cumprimento das sequências argumentativas utilizadas. Verifica-se, portanto, que orientar o discente de graduação sobre esses mecanismos pode instrumentalizá-lo com estratégias que corroborem para cumprindo o teor argumentativo esperado no gênero monografia.

Palavras-chave: Monografia; Argumentação; Operadores argumentativos.

\section{Introdução}

Os símbolos mediam as relações do homem com a natureza e com os seus semelhantes. Nesse relacionamento entre o homem e a linguagem, ocorre a interação social por intermédio da língua, caracterizada, sobretudo, pela

\footnotetext{
" É doutora em Linguística Aplicada pela Universidade Estadual de Campinas, onde também realizou o curso de mestrado em Linguística Aplicada. Atualmente, é professora adjunta do Departamento de Estudos Linguísticos e Literários da Universidade Estadual do Sudoeste da Bahia e docente do quadro permanente do Programa de Pós-Graduação em Linguística (PPGLin-UESB), campus de Vitória da Conquista, atuando na área de Linguística de Texto. Desenvolve, atualmente, projeto de pesquisa sobre processo de construção de textos, gênese de textos, relação entre estilo individual e estilo de gênero, crítica genética, autoria e ensino de texto. E-mail: marciahelenad@yahoo.com.br

** Mestra em Linguística, na linha de pesquisa de Texto, Significado e Discurso, pelo Programa de pós-graduação em Linguística (PPGLin/ UESB). Atuou como docente na área de Linguagens, em um colégio estadual da Bahia e, atualmente, ocupa um cargo de gestora de um colégio da rede estadual da Bahia. Cursou graduação em Letras pela Universidade Estadual do Sudoeste da Bahia (UESB), onde participou de dois projetos de pesquisa de iniciação científica, nas áreas de Sintaxe e de Aquisição da Linguagem. Pós-graduada em Língua Portuguesa e Língua Estrangeira (UNINTER) e em Língua Portuguesa e Literatura Brasileira (FACEI). E-mail: jaquelinefeitoza@gmail.com
}

Data de submissão: ago. 2021 - Data de aceite: out. 2021 http://dx.doi.org/10.5335/rdes.v17i3.11124 
argumentatividade. Nesse sentido, podemos postular, com Koch e Elias (2016), que argumentar é humano, pois, seja por escrito ou oralmente, as nossas interações são permeadas de argumentação.

Em determinadas construções comunicacionais, por conseguinte, a argumentação é revelada nas intenções do enunciador em posicionar-se diante de determinado assunto. Essa intencionalidade apresenta-se em gêneros fundamentalmente argumentativos, como em trabalhos comumente solicitados para conclusão de cursos de graduação, mais conhecidos como monografias ${ }^{1}$. Nesse gênero científico-acadêmico, o escrevente cumpre o papel de sujeito pesquisador e, como tal, segue, para sua elaboração, determinada estrutura composicional. Assim, para alcançar o teor argumentativo pretendido, é preciso manusear os recursos da textualidade que auxiliam na argumentatividade esperada.

Tendo em vista $o$ ato de argumentar e considerando o contexto social e discursivo que envolve o gênero monografia, vimos a necessidade de investigar como determinado sujeito utiliza mecanismos argumentativos na produção desse gênero, nessa etapa de sua formação/ escolarização. Dentre esses mecanismos, nos deteremos em investigar, na seção de introdução de uma monografia, a ocorrência (ou não) dos propósitos comunicativos, conforme Swales (2004), e a ocorrência dos operadores argumentativos, tendo como apoio o conceito de sequência argumentativa proposto do Adam (2008; 2009b; 2009c), visto que esses operadores são responsáveis pelo encadeamento dos enunciados, estruturando-os em textos e determinando sua orientação argumentativa e discursiva, como esclarece Koch (2011). Nosso interesse nessa seção em específico da monografia reside no fato de podermos perceber nela propósitos comunicativos em que transparecem o posicionamento do escrevente, a exemplo da justificativa da pesquisa, da questão posta para a investigação, dos objetivos expostos, da hipótese defendida pelo escrevente e da escolha metodológica a ser adotada. Comunicativamente, essas partes demonstram "o porquê" e "o como" a pesquisa foi desenvolvida, o que nos permite observar o posicionamento argumentativo realizado pelo graduando.

Isso posto, apresentamos nossa questão: como os elementos da textualidade ligados aos operadores argumentativos e aos aspectos sociorretóricos auxiliam o escrevente, concluinte de curso de graduação, no nível argumentativo necessário para compor o gênero monografia? Para responder a essa pergunta, investigamos, cientificamente, a seção de introdução de uma monografia da área de Ciências Humanas, do Curso de Comunicação Social, oriunda de uma universidade pública do estado da Bahia.

Para realização dessa investigação, partimos da hipótese de que o estudan- 
te universitário, ainda que concluinte de um curso de graduação, apresenta dificuldades no emprego de aspectos da textualidade que podem auxiliar na construção do nível argumentativo próprio do gênero monografia, tomando por base trabalhos de Motta-Roth e Hendges (2010), Marinho (2010), Simões (2002) e Figueiredo e Bonini (2006), cujas abordagens residem na discussão acerca da produção da escrita acadêmica.

Nossa discussão segue a seguinte sequência de abordagens: para versar sobre as características próprias do gênero monografia, levaremos em consideração as perspectivas dos seguintes teóricos: Souza e Silva (2017), que discorre sobre esse gênero, além de nos valermos da abordagem sociorretórica de Swales (2004), discutida no trabalho de Motta-Roth e Hendges (2010). Com o objetivo de expormos o delineamento das sequências textuais, apresentaremos os postulados de sequência textual de Jean-Michel Adam (2008; 2009b; 2009c), discutidos por Ribeiro (2012). Por fim, apresentaremos as contribuições dos operadores argumentativos para a elaboração das sequências argumentativas, tendo em vista as discussões de Koch (2011), e Koch e Elias (2016). Seguiremos apresentando nossas análises acerca do corpus selecionado para pesquisa e, por fim, apresentaremos nossas considerações finais a respeito da seção da monografia analisada, discutindo a obtenção, ou não, do nível comunicativo e argumentativo pelo escrevente, finalizando, assim, o que nos dispomos a investigar.

\section{O gênero Monografia}

O gênero monografia é um trabalho científico que versa sobre uma temática particular. De acordo com Souza e Silva (2017), a monografia, como o próprio nome indica, é um trabalho individual, cujo formato deve obedecer ao gênero científico, sendo claro e estruturalmente lógico, ao apresentar os resultados da pesquisa desenvolvida. Esse gênero se pauta em uma ação social que atenda à cultura acadêmica, com vistas à conclusão de um curso de nível superior de graduação ou de pós-graduação latu sensu.

A produção da monografia ocorre seguindo uma hierarquia de saberes partilhados, pois a construção desse gênero acontece depois do percurso de todo o curso; não é tarefa para ingressantes, como fundamentam Souza e Silva (2017) sobre os sujeitos produtores desse trabalho:

Os seus sujeitos produtores de monografia poderiam ser considerados como membros experientes em suas comunidades acadêmicas de pertença, haja vista que, para a produção deste gênero, passaram por etapas anteriores de desenvolvimento da escrita acadêmica, em que adentram na academia, tentam se inserir e ser reconhecidos no meio, passam a pertencer a este contexto, até o momento em que seu trabalho de conclusão de curso revela todo o percurso de aprendizagem. Entretanto, mesmo que 
concluintes em seus cursos de graduação, são iniciantes no fazer-científico. Por conseguinte, por representatividade, o sujeito se sente membro na monografia de especialização; é membro iniciante na dissertação de mestrado; é membro intermediário na tese de doutorado e é membro experiente quando é considerado pesquisador pelo CNPq (SOUZA; SILVA, 2017, p. 142, grifo das autoras).

Para este trabalho, discutiremos a proposta de Swales (2004) sobre a definição de gêneros ${ }^{2}$ através de metáforas ${ }^{3}$, uma vez que esse autor postula que as várias formas de compreender os gêneros devem ser aceitas, justificando a adoção de procedimentos metafóricos para resgatar especificidades relevantes dos gêneros. Essa proposta de Swales (2004) aqui exposta tem como objetivo buscar entender o contexto sociorretórico que circunscreve os gêneros.

Os aspectos retóricos concernentes ao propósito comunicativo de introduzir a pesquisa, postulados por Swales (2004), atribuem funções dos gêneros que atendam a uma perspectiva multifacetada, considerando que esses gêneros podem ter mais de um propósito comunicativo, e os objetivos são denominados concepções metafóricas dos gêneros, quais sejam: I) ação social, na orientação de ações retóricas efetivas; II) padrões de linguagem tanto social quanto retoricamente partilhados; III) espécies biológicas, por seguirem mudanças funcionais na linha do tempo (presente, passado e futuro); IV) as famílias de protótipos; V) as instituições, tendo em vista os processos de produção e recepção típicos; e VI) os atos de fala, por meio de discursos direcionados.

Baseado nessa classificação, Swales (2004) desenvolve o conceito de prototipicidade, trazendo a justificativa de que as concepções metafóricas acima expostas levam ao entendimento de que os protótipos dos gêneros são capazes de influenciar e restringir a escolha do conteúdo e do estilo desse gênero através do contexto em que está inscrito. No entanto, a partir da definição de gêneros através de metáforas, Swales (2004) fundamenta que as várias formas de compreendê-los podem ser aceitas, pois os procedimentos metafóricos permitem considerar as especificidades que circunscrevem o contexto de produção e recepção dos gêneros. Em vista desse caráter mais flexível, também considera que o gênero pode ter mais de um propósito; entretanto, o linguista recomenda ao analista do texto iniciar pelo propósito comunicativo oficial do gênero e, na sequência, repensar tal propósito, na medida em que estuda o contexto e o entendimento sobre esse gênero.

Isso posto, passemos a observar as estruturas esquemáticas prototípicas do gênero monografia. Tais estruturas são aqui relatadas no sentido de descrever os propósitos específicos evidenciados no gênero. Desse modo, exporemos os elementos estruturais tradicionalmente relatados em manuais de metodologia 
científica, na coluna esquerda do Quadro 1, e a estrutura, conforme os propósitos comunicativos, à direita do mesmo quadro:

Quadro 1 - Visão geral da organização retórica de monografias

\begin{tabular}{|c|c|}
\hline Elementos estruturais & Propósitos comunicativos \\
\hline Elementos pré-estruturais & SITUAR A PESQUISA \\
\hline $\begin{array}{l}\text { Capa (obrigatório), lombada (opcional), folha de ros- } \\
\text { to (obrigatório), errata (opcional), folha de aprovação } \\
\text { (obrigatório), dedicatória(s) (opcional), agradecimento(s) }\end{array}$ & \multirow{6}{*}{$\begin{array}{c}\text { FUNDAMENTAR TEORICAMENTE } \\
\text { RELATAR METODOLOGIA } \\
\text { ANALISAR DADOS } \\
\text { CONCLUIR A PESQUISA } \\
\text { CREDENCIAR O TRABALHO }\end{array}$} \\
\hline $\begin{array}{l}\text { (opcional), resumo (na língua vernácula (obrigatório), re- } \\
\text { sumo na língua estrangeira (obrigatório), lista de ilustra- } \\
\text { ções (opcional), lista de tabelas (opcional), lista de abre- }\end{array}$ & \\
\hline $\begin{array}{l}\text { viaturas (opcional), lista de símbolos (opcional) e sumário } \\
\text { (obrigatório). }\end{array}$ & \\
\hline $\begin{array}{l}\text { Elementos textuais } \\
\text { Introdução, desenvolvimento e conclusão. }\end{array}$ & \\
\hline Elementos pós-textuais & \\
\hline $\begin{array}{l}\text { Referências (obrigatório), glossário (opcional), } \\
\text { apêndice(s) (opcional) e índice(s) (opcional). }\end{array}$ & \\
\hline
\end{tabular}

Fonte: Souza e Silva (2017, p. 147 apud SOUZA, 2014).

Os elementos estruturais do gênero monografia são normatizados pela Associação Brasileira de Normas Técnicas (ABNT) e pelos manuais de metodologia científica, conforme apresentado na coluna esquerda do quadro 1, anterior. Essa normatização é constantemente consultada pelos graduandos no momento da elaboração de seus textos. Apresentamos aqui uma ressalva de Souza e Silva (2017), ou seja, a monografia atende a propósitos comunicativos que desempenham funções escritas específicas para a organização esquemática do gênero; logo, sua estruturação não necessariamente deve atender a seções fixas, conforme orientam os manuais. Assim, as autoras justificam que é pertinente analisar as monografias pelos propósitos a que servem, quais sejam: "situar, introduzir, fundamentar teoricamente, relatar metodologia, concluir e acrescentar a pesquisa/o trabalho" (SOUZA; SILVA, 2017, p. 148), como descrito na coluna direita do quadro 1.

Ao nos atentarmos para a investigação do gênero monografia, buscamos compreender a cientificidade esperada na esfera acadêmica, por se estabelecer através do movimento de construção e reconstrução de conhecimentos validados, em contínua apropriação, reflexão e contestação de saberes produzidos, conforme discutem Souza e Silva (2017). Passemos, na próxima seção, às especificidades da sequência argumentativa. 


\section{A sequência argumentativa e os operadores argumentativos}

Para iniciar esta seção, esclarecemos a relação existente entre as sequências argumentativas e os operadores argumentativos. Conforme discute Koch (2011), esses operadores são responsáveis pelo encadeamento de enunciados, estruturando-os em textos e determinando sua orientação discursiva, podendo, por conseguinte, auxiliar o encadeamento de enunciados presentes na composição da sequência argumentativa. Diante disso, abordando a ocorrência desses operadores, e em que medida eles contribuem (ou não) para o desenvolvimento argumentativo do texto analisado, podemos observar a formação da sequência argumentativa, de acordo com o esquema prototípico proposto por Adam (2009c). Diante do exposto, apresentamos, a seguir, a noção de sequências argumentativas e a contribuição dos operadores argumentativos para sua composição.

Argumentar consiste na oposição de enunciados, de acordo com os postulados de Adam (2009b) acerca da construção de sequências argumentativas. Para o teórico, esses enunciados são interligados por operadores argumentativos. A fim de delimitarmos nossa atenção para as sequências argumentativas, apresentamos o esclarecimento de Adam (2009b) sobre uma clara distinção entre orientação argumentativa e sequência argumentativa:

[...] não se deve confundir o fato de que todos os textos comportam uma orientação argumentativa com o fato de que existe este tipo de colocação em sequência cujo grau zero é certamente representado pelo silogismo e pelo entimema (ADAM, 2009b apud RIBEIRO, 2012, p. 42).

Adam (2009c) chama a atenção de que a argumentação consiste em movimentos de demonstração de uma tese e refutação dessa mesma tese, conforme citação a seguir:

Um discurso argumentativo [...] se coloca sempre em relação a um contra discurso efetivo ou virtual. A argumentação é, por isso, indissociável da polêmica. Defender uma tese ou uma conclusão é sempre defendê-la contra outras teses ou conclusões, do mesmo modo que entrar em uma polêmica não implica somente um desacordo [...], mas, sobretudo, a posse de contra-argumentos. Esta propriedade que a argumentação tem de ser submissa à refutação me parece ser uma de suas características fundamentais e a distingue nitidamente da demonstração ou da dedução, que, no interior de um sistema dado, se apresentam como irrefutáveis (ADAM, 2009c apud RIBEIRO, 2012, p. 43).

Diante dessa proposta, Adam (2009c) assim expõe o esquema de sequência argumentativa prototípica, conforme a Figura 1, a seguir: 
Figura 1 - Esquema simplificado de uma sequência argumentativa

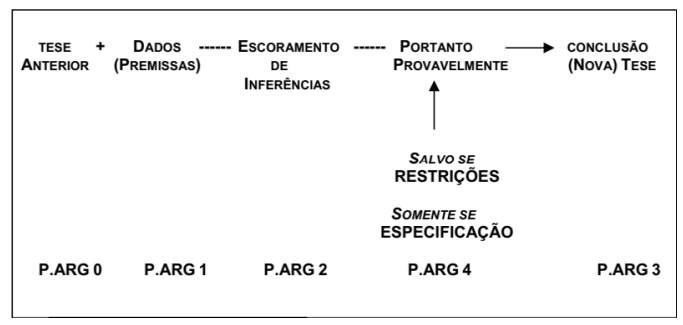

Fonte: Adam (2009c apud RIBEIRO, 2012, p. 42).

De acordo com o teórico, a sequência argumentativa se dá a partir dos movimentos de demonstração e/ou justificativa de uma tese e da refutação de outras teses ou argumentos. Assim, a partir dessas premissas, chega-se a uma conclusão ou afirmação, conforme explanação de Ribeiro (2012). Dito de outro modo, na sequência argumentativa, é apresentada uma posição favorável ou desfavorável em relação a uma tese inicial e a posição de quem enuncia é sustentada com base em argumentos ou provas.

Em conformidade com o esquema proposto por Adam (2009c), a tese anterior e as inferências não precisam, necessariamente, estar explícitas no texto: elas podem ser determinadas mediante o sentido do enunciado. Os elementos compostos pelos dados (ou afirmações) e a conclusão (que é a opinião do enunciador) podem compor uma nova sequência argumentativa.

É bom lembrar que as sequências não seguem padrões rígidos. Desse modo, a ordem estabelecida na sequência argumentativa pode sofrer variações, ocorrendo tanto de forma progressiva (D então C), quanto de forma regressiva (D porque $\mathrm{C}$, em que se dá prioridade à explicação, para justificar a afirmação anterior), conforme explica Ribeiro (2012). Ainda, resta-nos esclarecer sobre os níveis da sequência argumentativa apontados por Adam (2008). Segundo o autor:

a) o nível justificativo (soma das proposições argumentativas: P arg1 + P. arg2 + P. arg3), a estratégia argumentativa é dominada pelos conhecimentos apresentados e o interlocutor tem pouca relevância [...] b) o nível dialógico ou contra-argumentativo (soma das proposições argumentativa $P$. $\arg 0+$ + P. arg4), a estratégia argumentativa visa a uma transformação dos conhecimentos, a argumentação é negociada com um contra-argumentador real ou potencial, o que caracteriza o aspecto dialógico da sequência argumentativa (ADAM, 2008, p. 233-234 apud RIBEIRO, 2012, p. 44, grifo da autora).

Dessa forma, Adam (2008) nos fornece uma importante observação, pois, com a análise dos níveis argumentativos, é possível mensurar o grau de argumentatividade do escrevente. É sobre o segundo nível apontado pelo teórico, o contra-argumentativo, que observaremos o posicionamento argumentativo do sujeito desta pesquisa, ou a visada argumentativa, na seção do texto por nós separado para análise, uma vez que esse nível explicita o posicionamento argumentativo do escrevente. 
Em suma, Adam, autor da teoria das sequências textuais, afirma que elas são, ao mesmo tempo, categorias cognitivas e produtos culturais da sociedade. $\mathrm{O}$ conceito de sequências textuais, em específico das sequências argumentativas e expositivas, será um dos nossos pontos de apoio para a análise que propomos. Justificamos tal escolha diante do caráter científico do gênero, que apresenta um discurso que é pautado no já dito, e tal característica requer um caráter argumentativo e expositivo em sua elaboração.

Para a composição dessas sequências, são necessários elementos de concatenação textual denominados de operadores argumentativos. Koch (2011) designa como operadores argumentativos morfemas e vocábulos pertencentes a categorias gramaticais variadas, a exemplo de conectivos, conjunções, advérbios, locuções adverbiais ou aqueles em que não há uma classificação específica. Esses operadores têm por função auxiliar na direção argumentativa do enunciado. São, portanto, responsáveis pela direção argumentativa e discursiva, o que levou a linguista a classificá-los como operadores discursivos. Tal estudo tem sua fundamentação em Ducrot (1997), que, a partir de investigações com operadores argumentativos, defende a tese de que a orientação argumentativa está na própria língua, descartando a dependência a fatos lógicos, relação que era frequente em concepções tradicionais da argumentação.

$\mathrm{Na}$ construção desses procedimentos argumentativos, concordamos com Koch (2011) e Koch e Elias (2016) acerca da relevância dos operadores argumentativos/ discursivos. Alguns desses operadores, bem como suas funções, citados pelas autoras, exemplificamos no Quadro 2, a seguir.

Quadro 2 - Os operadores argumentativos/discursivos

1. Operadores que somam argumentos a favor de uma mesma conclusão: e, também, ainda, nem (e não), não só... mas também, tanto... como, além de, além disso etc.;

2. Operadores que indicam o argumento mais forte de uma escala a favor de uma determinada conclusão: até, até mesmo, inclusive (quando a escala é orientada para a afirmação) e nem, nem mesmo (quando a escala é orientada para a negação);

3. Operadores que contrapõem argumentos orientados para conclusões contrárias: mas, porém, contudo, todavia, no entanto, entretanto, embora, ainda que, posto que, apesar de (que);

4. Operadores que introduzem uma conclusão com relação a argumentos apresentados em enunciados anteriores: logo, portanto, pois, por isso, por conseguinte, em decorrência etc.;

5. Operadores que introduzem uma justificativa ou explicação relativamente ao enunciado anterior: porque, porquanto, já que, pois, que, visto que, como etc.;

Fonte: Koch (2011, p.102-106) e Koch e Elias (2016, p. 61-75).

Portanto, Koch (2011) ressalta a importância de estudar os operadores 
argumentativos/discursivos, visto que apresentam natureza argumentativa e retórica. Dessa forma, esses elementos de valor argumentativo conduzem a orientação argumentativa global, pois direcionam o interlocutor a determinado tipo de conclusões.

\section{Análise do corpus: elementos argumentativos no gênero monografia}

O gênero por nós analisado refere-se a uma monografia intitulada $A$ interatividade, o modelo de negócio e a distribuição de conteúdo nos sites jornalísticos nativos on-line brasileiros. $\mathrm{O}$ informante foi estudante do curso de bacharelado em Comunicação Social, com habilitação em Jornalismo, de uma universidade pública da Bahia, sendo seu texto apresentado e obteve aprovação em 2017. Ele será por nós denominado IHC (sigla de Informante da área de Humanas, do curso de Comunicação), com o objetivo de resguardar sua identidade. A monografia é constituída das seções de introdução, aporte teórico, metodologia e resultados e considerações finais, num total de 86 páginas, incluindo referências e anexos.

Como já justificado a respeito de nosso recorte analítico, selecionamos a seção de introdução para análise no presente trabalho. A razão de tal seleção reside no fato de podermos observar se há propósitos comunicativos em que transpare- çam o posicionamento do escrevente, a exemplo da justificativa da pesquisa, da questão posta para a investigação, dos objetivos expostos, da hipótese defendida pelo escrevente e da escolha metodológica a ser adotada. Ademais, nessa seção, podemos, também, verificar construções que demandam maior posicionamento argumentativo do escrevente, a exemplo da apresentação da justificativa e da hipótese da pesquisa. A fim de observarmos o cumprimento do teor comunicativo de argumentativo da seção de introdução, empregamos duas categorias analíticas, como ilustra o Quadro 3, a saber:

Quadro 3 - Categorias analíticas

- Aspectos sociorretóricos

- Os operadores argumentativos na composição das sequências.

Fonte: elaboração própria.

Observemos a introdução elaborada por IHC, a seguir, na subseção de aspectos sociorretóricos.

\section{Aspectos sociorretóricos}

Nesta subseção, observaremos a estrutura esquemática da seção de introdução, baseada nos propósitos comunicativos específicos do gênero monografia.

Exporemos, no Quadro 4, a seguir, a introdução elaborada por IHC, à esquerda, e os aspectos sociorretóricos concernentes ao propósito comunicativo de introduzir a pesquisa, à direita do quadro: 


\begin{tabular}{|c|c|}
\hline Propósito comunicativo: introduzir pesquisa & Movimentos retóricos \\
\hline 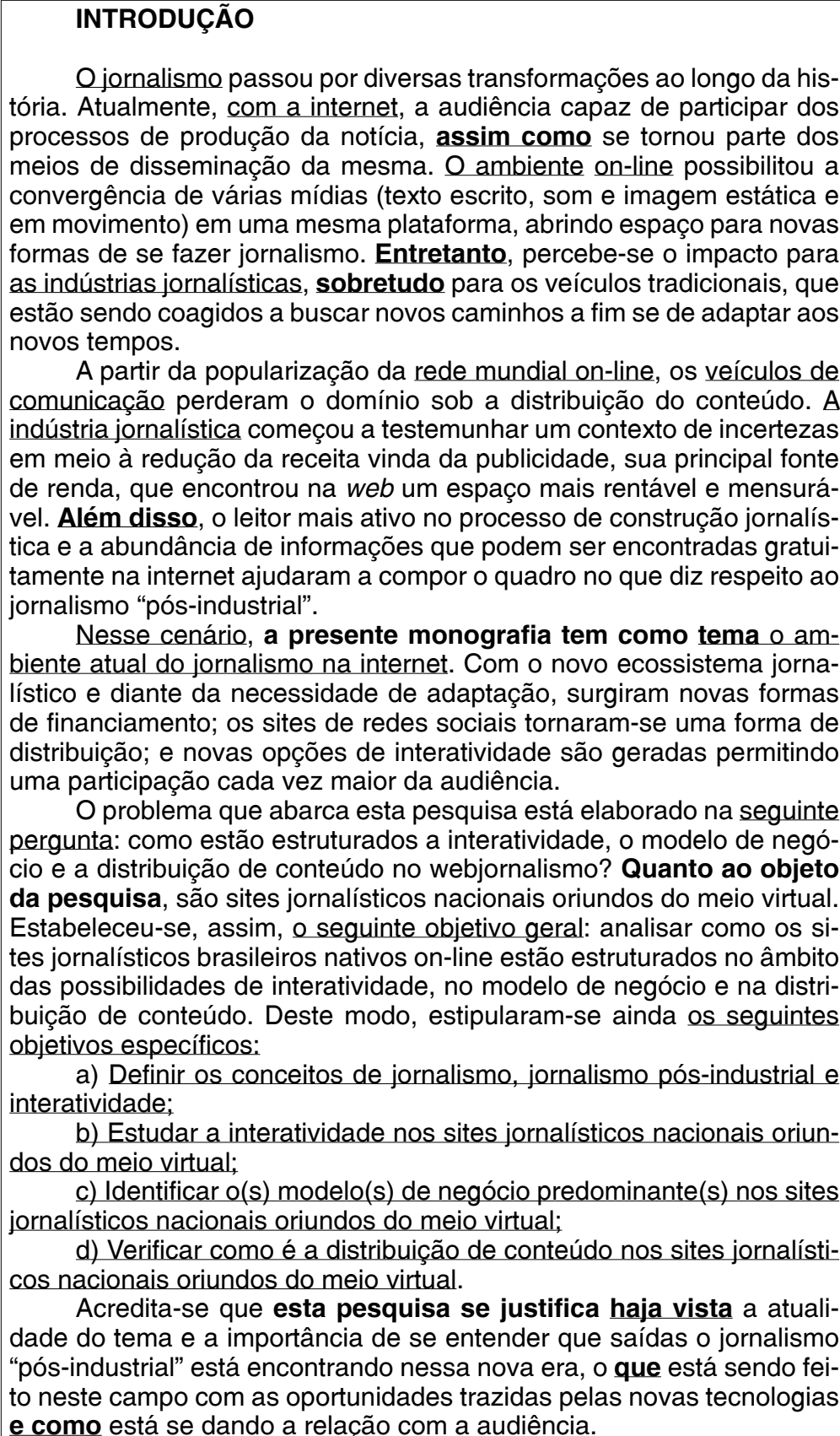 & 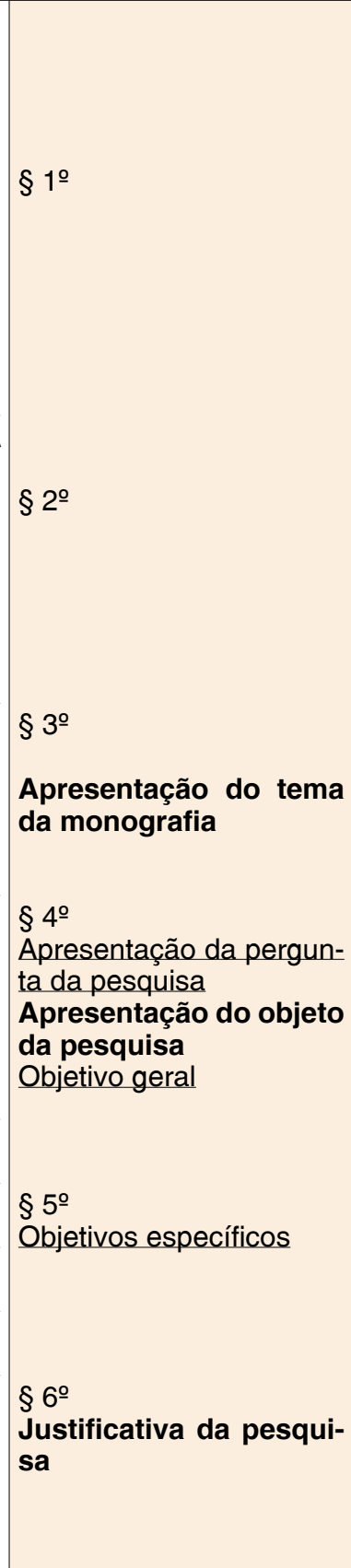 \\
\hline
\end{tabular}


(conclusão)

\begin{tabular}{|c|c|}
\hline $\begin{array}{l}\text { Para compreender o jornalismo desde o nascimento dos primei- } \\
\text { ros jornais e pensamentos teóricos a esse respeito, refletiu-se acerca } \\
\text { das considerações do estudioso Tobias Peucer. Para versar sobre em } \\
\text { que consiste o jornalismo, as perspectivas dos seguintes teóricos fo- } \\
\text { ram discutidas: Robert Park (1955 apud MACHADO, 2005), que profere } \\
\text { sobre o conhecimento jornalístico por meios das definições de conhe- } \\
\text { cimento "de" e "acerca de"; Adelmo Gennro Filho (2012), que defende o } \\
\text { jornalismo como instituição social que supera as bases do capitalismo } \\
\text { em que foi originado; Eduardo Meditsch (1997), que discute o jornalis- } \\
\text { mo como forma de conhecimento; e Otto Groth (2011), que trata das ca- } \\
\text { racterísticas essenciais dos jornais. Para abordar o jornalismo feito no } \\
\text { ambiente on-line, considerou-se a discussão proposta por Luciana Mie- } \\
\text { Iniczuk (2003) quanto às nomenclaturas usadas para fazer referência a } \\
\text { este. Observaram-se ainda as características presentes nesse tipo de } \\
\text { jornalismo citadaspor Jo Bardoel e Mark Deuze (2001). Além disso, os } \\
\text { autores Christopher William Anderson, Emily Bell e Clay Shirky (2013), } \\
\text { assim como Caio Túlio Costa (2014), discutem o chamado jornalismo } \\
\text { pós-industrial, enquanto_Alejandro Rost (2014) aborda a interatividade } \\
\text { sob o âmbito jornalístico e Raquel Recuero (2009) discorre as redes } \\
\text { sociais em vista dessa prática. } \\
\text { No primeiro capítulo (Conceitos do jornalismo), apresentam- } \\
\text {-se os pensamentos teóricos acerca do jornalismo enquanto forma de } \\
\text { conhecimento e as implicações dessa prática na web. No segundo } \\
\text { capítulo (Jornalismo e mudanças acarretadas pela internet), o novo } \\
\text { ecossistema ocasionado pela chegada da internet, os conceitos de in- } \\
\text { teratividade e a relação dos sites de redes sociais com o jornalismo } \\
\text { são debatidos. Já no terceiro_capítulo (Metodologia e resultados), o } \\
\text { percurso metodológico, a apresentação dos resultados e sua discussão } \\
\text { estão presentes. Após a realização da seleção dos sites que consis- } \\
\text { tem nesta pesquisa, estes foram então visitados de modo a verificar } \\
\text { a aplicação quantitativa de itens escolhidos para observar os modelos } \\
\text { de negócio, as formas de distribuição e as opções de interatividade } \\
\text { disponíveis. }\end{array}$ & $\begin{array}{l}\S 7^{\circ} \\
\text { Delineamento teórico da } \\
\text { pesquisa } \\
\S 8^{\circ} \\
\begin{array}{l}\text { Apresentação da estru- } \\
\text { tura organizacional da } \\
\text { monografia. }\end{array}\end{array}$ \\
\hline
\end{tabular}

Fonte: Corpus coletado para pesquisa (grifos nossos).

Observamos que a produção da monografia no espaço social universitário atende a uma estrutura esquemática prototípica, que contempla tanto a criatividade dos sujeitos produtores quanto sua capacidade sociocognitiva na produção de gêneros. Assim, podemos observar, no Quadro 4, o cumprimento desse protótipo requerido no ambiente institucional da universidade, pois, de acordo com Souza e Silva (2017), os "pro- pósitos comunicativos são construções e ações textuais diversas que caracterizam a organização esquemática dos gêneros" (SOUZA; SILVA, 2017, p. 148). No propósito de introduzir a pesquisa por nós ilustrado no quadro 4 , há uma ação textual específica dentro do gênero monografia, qual seja: os elementos presentes na coluna "movimentos retóricos" exemplificam características essenciais que servem para a construção das intro- 
duções de monografias. Observamos que esses aspectos são encontrados na seção de introdução de IHC, apresentando, na ordem, os seguintes movimentos:

a) apresentação do tema da pesquisa: nesse movimento retórico, o escrevente, no terceiro parágrafo, apresenta a seguinte declaração: "Nesse cenário, a presente monografia tem como tema o ambiente atual do jornalismo na internet", cumprindo o movimento retórico de apresentação do tema da pesquisa.

b) apresentação da pergunta da pesquisa: o escrevente inicia o quarto parágrafo realizando o movimento retórico de pergunta da pesquisa: "O problema que abarca esta pesquisa está elaborado na seguinte pergunta: como estão estruturados a interatividade, o modelo de negócio e a distribuição de conteúdo no webjornalismo"?

c) apresentação do objeto da pesquisa: também, no quarto parágrafo, o informante descreve o propósito comunicativo de relatar o objeto de sua monografia, a saber: "Quanto ao objeto da pesquisa, são sites jornalísticos nacionais oriundos do meio virtual".

d) objetivos geral e específicos: nos parágrafos quarto e quinto, o escrevente expõe seu objetivo principal e seus objetivos espe- cíficos, cumprindo o propósito comunicativo de apresentar os objetivos que nortearão sua pesquisa, a saber: "Estabeleceu-se, assim, o seguinte objetivo geral: analisar como os sites jornalísticos brasileiros nativos on-line estão estruturados no âmbito das possibilidades de interatividade, no modelo de negócio e na distribuição de conteúdo. Deste modo, estipularam-se ainda os seguintes objetivos específicos: a) Definir os conceitos de jornalismo, jornalismo pós-industrial e interatividade [...]"

e) justificativa da pesquisa: o propósito comunicativo de justificar a pesquisa é apresentado no sexto parágrafo: "Acredita-se que esta pesquisa se justifica haja vista a atualidade do tema e a importância de se entender que saídas o jornalismo 'pós-industrial' está encontrando nessa nova era, o que está sendo feito neste campo com as oportunidades trazidas pelas novas tecnologias e como está se dando a relação com a audiência".

f) delineamento teórico da pesquisa: no sétimo parágrafo, o escrevente realiza o movimento retórico de apresentar o aporte teórico de sua pesquisa: "Para compreender o jornalismo desde o nascimento 
dos primeiros jornais e pensamentos teóricos a esse respeito, refletiu-se acerca das considerações do estudioso Tobias Peucer. [...]".

g) apresentação da estrutura organizacional da pesquisa: por último, no parágrafo oitavo, IHC cumpre o propósito comunicativo de descrever a estrutura organizacional de seu texto, do qual expomos apenas essa passagem, a critério de ilustração: "No primeiro capítulo (Conceitos do jornalismo), apresentam-se os pensamentos teóricos acerca do jornalismo [...]".

Todos esses elementos presentes na introdução da monografia de Comunicação, como podemos perceber no Quadro 4 , anteriormente, contribuem para 0 propósito comunicativo de introduzir a pesquisa, pois realiza os movimentos retóricos requeridos no espaço social da universidade, cumprindo a estrutura esquemática prototípica desse contexto no que se refere à produção do gênero monografia. Em síntese, diante dos dados apresentados, defendemos que ter certa consciência da abordagem sociorretórica, à semelhança do proposto por Swales (2004), favorece a ação do sujeito pesquisador no propósito de introduzir a pesquisa, pois entendemos que a organização esquemática do gênero é caracterizada pelas construções e ações textuais diversas dos propósitos comunicativos desse gênero. Isso posto, passemos para a análise acerca dos operadores argumentativos presentes na seção de introdução, na subseção a seguir.

\section{Os operadores argumentativos na composição das sequências}

Para iniciar esta subseção, relembramos a função dos operadores argumentativos: apresentam uma natureza argumentativa e retórica, tendo por função conduzir a orientação argumentativa global. Diante disso, cumpre-nos abordar a ocorrência desses operadores, e em que medida eles contribuem (ou não) para o desenvolvimento argumentativo do texto analisado.

$\mathrm{Na}$ introdução de IHC, notamos a presença da estrutura prototípica da sequência argumentativa no nível justificativo (soma das proposições argumentativas: P. $\arg 1+$ P. $\arg 2+$ P. $\arg 3)$, como demonstrado no excerto (01):

Acredita-se que esta pesquisa se justifica (P.ARG 3: conclusão) haja vista a atualidade do tema e a importância de se entender que saídas o jornalismo "pós-industrial" está encontrando nessa nova era, (P.ARG 2: justificativa) o que está sendo feito neste campo com as oportunidades trazidas pelas novas tecnologias e como está se dando a relação com a audiência. (P.ARG 2: justificativa). 
Nessa sequência, os operadores "haja vista" e "e como" atuam como auxílio argumentativo no excerto (01). O primeiro operador introduz uma explicação sobre a afirmação anterior da presença de uma justificativa para a pesquisa (P. Arg. 3). Já o segundo operador, "e como", soma o argumento "relação com a audiência" a favor da mesma conclusão, ou seja, de que a pesquisa se justifica (P. Arg 3).

O nível dialógico ou contra-argumentativo (soma das proposições argumentativas P. Arg $0+$ P. Arg 4) é também desenvolvido na introdução de IHC, nos parágrafos 1 e 2 . Talvez, a ocorrência escassa de uma sequência argumentativa tão prototípica se justifique pelo caráter comunicativo da introdução, marcada pela apresentação geral da pesquisa, portanto, mais expositivo do que argumentativo. Logo, foram poucas as partes dessa seção em que encontramos as visadas argumentativas do escrevente. Mesmo assim, nesses momentos, o enunciador apresenta um posicionamento dialógico ou contra-argumentativo, inclusive, com a presença do operador contrajuntivo "entretanto", que conduz a uma nova argumentação, conforme demonstrado no próximo excerto. Então, observemos o excerto (02), ilustrativo de uma sequência prototípica, retirado da introdução de IHC:
O jornalismo passou por diversas transformações ao longo da história (P. Arg 0). Atualmente, com a internet, a audiência é capaz de participar dos processos de produção da notícia (P. Arg 1), assim como se tornou parte dos meios de disseminação da mesma (P. Arg 2). O ambiente on-line possibilitou a convergência de várias mídias (texto escrito, som e imagem estática e em movimento) em uma mesma plataforma, abrindo espaço para novas formas de se fazer jornalismo. Entretanto, percebe-se o impacto para as indústrias jornalísticas (P. Arg 4), sobretudo para os veículos tradicionais, que estão sendo coagidos a buscar novos caminhos a fim se de adaptar aos novos tempos (P. Arg 3).

No excerto (02), temos a presença do operador "atualmente", cuja função é marcação temporal, ligando a tese anterior "O jornalismo passou por diversas transformações ao longo da história" (P. Arg 0$)$ ao (P. Arg 1) à premissa "com a internet, a audiência é capaz de participar dos processos de produção da notícia”. Na sequência, o emprego do operador "assim como" introduz a soma do argumento "se tornou parte dos meios da mesma", presente na sequência como P. Arg 2, antecedendo as inferências que estão por vir, isto é, "O ambiente on-line possibilitou a convergência de várias mídias (texto escrito, som e imagem estática e em movimento) em uma mesma plataforma, abrindo espaço para novas formas de se fazer jornalismo". Além desses argumentos, encontramos o elemento necessário 
para o desenvolvimento da escala prototípica completa, o P. Arg 4, cuja introdução se dá pelo operador argumentativo "Entretanto", responsável por contrapor argumentos orientados para uma conclusão contrária, qual seja: "o impacto para as indústrias jornalísticas”. Ainda na relação de oposição (P. Arg 4), como já sinalizamos, há a soma de argumento em favor dessa conclusão contrária, mediante o operador "sobretudo". Por fim, o excerto 2 completa a escala argumentativa prototípica com a presença do $\mathrm{P}$. Arg 3, concluindo o período introduzido pelo operador explicativo "que", relativo ao enunciado anterior "sobretudo para os veículos tradicionais", iniciando nova conclusão ou tese: "estão sendo coagidos a buscar novos caminhos a fim se de adaptar aos novos tempos". Temos, portanto, o cumprimento da escala argumentativa completa no parágrafo do excerto (02). Percebemos, através desse exemplo, a relevância dos operadores argumentativos para composição do gênero monografia.

Observemos, agora, o excerto (03), que também ilustra a escala argumentativa prototípica, conforme modelo desenvolvido por Adam (2009c):

A partir da popularização da rede mundial on-line, os veículos de comunicação perderam o domínio sob a distribuição do conteúdo (P. ARG 0). A indústria jornalística começou a testemunhar um contexto de incertezas em meio à redução da receita vinda da publicidade, sua principal fonte de renda, que encontrou na web um espaço mais rentável e mensurável (P. ARG 1). Além disso, (P.ARG 2) o leitor mais ativo no processo de construção jornalística e a abundância de informações que podem ser encontradas gratuitamente na internet ajudaram a compor o quadro no que diz respeito ao jornalismo "pós-industrial". Nesse cenário, (P. ARG 4) a presente monografia tem como tema o ambiente atual do jornalismo na internet. Com o novo ecossistema jornalístico e diante da necessidade de adaptação, surgiram novas formas de financiamento; (P. ARG 3) os sites de redes sociais tornaram-se uma forma de distribuição; e novas opções de interatividade são geradas permitindo uma participação cada vez maior da audiência.

No esquema apresentado por Adam (2009c) sobre a sequência argumentativa, a tese anterior e as inferências não necessariamente precisam estar presentes no texto, sendo determinadas pelo sentido do enunciado. No excerto (03), observamos o cumprimento da sequência argumentativa de nível dialógico ou contra-argumentativo completa, com a presença de tese anterior ( $P$. ARG 0) + dados (premissas P. ARG 1) + escoamento de inferenciais (P. ARG $2)+$ operador (P. ARG 4) + conclusão (P.ARG 3). Ademais, percebemos, no excerto (03), a presença de três operadores argumentativos que auxiliaram na construção da sequência: "a partir", "além disso" e "nesse cenário". O primeiro operador introduz a tese anterior: "da popularização da rede mundial on-line, 
os veículos de comunicação perderam o domínio sob a distribuição do conteúdo", funcionando como operador temporal; o segundo operador, "além disso", auxiliou na construção de inferências, em favor de uma mesma conclusão: "o leitor mais ativo no processo de construção jornalística e a abundância de informações que podem ser encontradas gratuitamente na internet ajudaram a compor o quadro no que diz respeito ao jornalismo 'pós-industrial"'. O terceiro operador, "nesse cenário", introduziu uma conclusão com relação aos argumentos apresentados anteriormente, ou seja, "a presente monografia tem como tema o ambiente atual do jornalismo na internet".

É importante salientar que as sequências não seguem padrões rígidos, podendo sofrer variação no modelo argumentativo, ocorrendo tanto de forma progressiva (D então C), quando de forma regressiva ( $D$ porque $C$ ). A ocorrência regressiva foi observada no excerto (01), dando prioridade à explicação para justificar a afirmação anterior, diante do nível justificativo da sequência, marcado pelos operadores "haja vista" e "e como", nos períodos "a atualidade do tema e a importância de se entender que saídas o jornalismo 'pós-industrial' está encontrando nessa nova era" e "como está se dando a relação com a audiência", respectivamente. Esses operadores argumentativos empregados na introdução funcionaram tanto para apresentar um nível mais justificativo da sequência quanto um nível mais dialógico, contra-argumentativo.

Concluímos que a sequência argumentativa está presente na seção analisada e que o propósito comunicativo de introduzir foi atingido, mesmo que o nível justificativo da sequência apareça na maior parte da seção. Essa escassez de contra-argumento, como já mencionamos, pode ser reflexo da natureza comunicativa da introdução, apresentado um panorama geral do texto.

\section{Conclusão}

Através deste estudo, buscamos investigar como o escrevente do gênero monografia, em análise, consegue realizar os movimentos retóricos de comunicação nessa seção investigada e, também, se emprega os operadores argumentativos necessários para auxiliar no cumprimento da função argumentativa desse texto. Dois critérios de análise foram aplicados: os aspectos sociorretóricos, embasados em estudos da teoria sociorretórica desenvolvida por Swales (2004) e discutida no trabalho de Motta-Roth e Hendges (2010) e os operadores argumentativos, conforme as considerações de Koch (2011), e Koch e Elias (2016), alicerçados no conceito de sequência argumentativa proposto do Adam (2008; 2009b; 2009c), discutidas por Ribeiro (2012). 
Quanto aos aspectos sociorretóricos, comprovamos que os propósitos comunicativos de introduzir pesquisa, conforme a abordagem sociorretórica, foram cumpridos na introdução em análise, pois o escrevente consegue realizar os movimentos retóricos requeridos no espaço social da universidade, cumprindo a estrutura esquemática prototípica desse contexto no que se refere à produção de introdução da monografia. Chegamos a essa conclusão com base nos aspectos sociorretóricos de Swales (2004) de prototipicidade de gêneros, ou seja, entendimento de que os protótipos dos gêneros são capazes de influenciar e restringir a escolha do conteúdo e do estilo através do contexto em que está inscrito. Em vista disso, reconhecer os protótipos, defende o linguista, é um importante procedimento a ser seguido pelo analista do texto. Então, constatamos que os movimentos realizados na sua introdução cumprem a funções retóricas de asseverar a importância do assunto, fazer generalização sobre ele, revisar itens de pesquisa prévia, fazer questionamentos, esboçar os objetivos, anunciar (apresentar) o tema da pesquisa, anunciar possíveis resultados (hipótese) e indicar a estrutura do artigo.

A respeito dos operadores argumentativos, comprovamos que, nos momentos que eles se fizeram presentes, houve o cumprimento da sequência argumentativa, tanto de nível explicativo quanto de nível discursivo. Percebemos, no entanto, que a ocorrência de sequência argumentativa foi escassa. Acreditamos que essa escassez, sobretudo de contra-argumento, pode ser reflexo da natureza comunicativa da introdução, que apresenta um panorama geral do texto, sendo, portanto, mais explicativo do que argumentativo, muito embora haja momentos em que o escrevente precisa se posicionar argumentativamente, quando da apresentação da justificativa, por exemplo.

Com base nos resultados relatados, podemos afirmar que a nossa hipótese se confirma em parte, ou seja, o escrevente da seção de introdução investigada apresenta dificuldades quanto ao emprego dos operadores argumentativos que poderiam auxiliar em um cumprimento de visadas argumentativas no gênero monografia. No entanto, esse escrevente cumpre os propósitos comunicativos de introduzir pesquisa, demonstrando uma produção ligada a uma prototipicidade dos propósitos comunicativos dessa seção. Mesmo que as visadas argumentativas se apresentem escassas nessa introdução, a apresentação de sua pesquisa permite visualizar um panorama geral de seu texto.

Os resultados até agora obtidos por este estudo apontam para reafirmar que tais elementos da textualidade se mostram promissores na condução das visadas argumentativas e, por conse- 
guinte, são recursos que podem auxiliar o escrevente num momento determinante, ao instrumentalizá-lo com estratégias que corroborem para a apresentação escrita de sua pesquisa, cumprindo o teor comunicativo e argumentativo esperado no gênero monografia.

\section{Notas}

1 Os trabalhos de conclusão de curso costumam ser chamados, na esfera acadêmica, de TCC. Essa sigla é a abreviação de Trabalho de Conclusão de Curso e é definida, segundo a NBR 14724/2005, como um documento que representa o resultado de um estudo em que 0 assunto escolhido deve expressar conhecimento oriundo de disciplina, módulo, curso, programa ou outros conhecimentos ministrados. O TCC pode se configurar sob a forma dos gêneros monografia, artigo científico, relato de caso e relatório de estágio, para cursos de graduação e, também, pode ser nomeado de dissertação ou tese, para cursos de pós-graduação stritu sensu de mestrado e doutorado, respectivamente. Portanto, a escolha do gênero irá depender do curso e da instituição de ensino.

2 De acordo com os estudos de Swales (1990), os gêneros são concebidos como classes de eventos comunicativos, podendo ser "aleatórios, idiossincráticos e motivados por um propósito único e distintivo". Além disso, são como ações linguísticas retóricas, que possibilitam à linguagem comunicar algo a alguém, para algum propósito, em momento e contexto específicos, por isso, são tidos como importantes ferramentas de ensino.

A partir da definição apresentada, o autor trabalha a noção de prototipicidade, através da compreensão de que "protótipos de gêneros são reconhecidos por uma lógica subjacente capaz de influenciar e restringir a escolha de conteúdo e estilo em contexto situado. Segundo o linguista, o reconhecimento dos protótipos é um dos procedimentos que um analista deve seguir, em um percurso que parte do contexto para o texto e projeta a organização de gêneros em movimentos retóricos e, consequentemente, seus aspectos textuais e linguísticos" (SOUZA; SILVA, 2017, p. 138).
3 Acerca do trabalho com gêneros sob a perspectiva metafórica, Swales esclarece: "[...] acredito que temos de caracterizar gêneros como um esforço metafórico, essencialmente, para que as várias metáforas possam ser chamadas em proporções variadas, de acordo com as circunstâncias, a sua própria luz em nossos entendimentos" (SWALES, 2004, p. 61).

\section{Abstract}

In this article, communication aspects of socio-rhetoric and mechanisms related to textuality called argumentative operators are addressed, in the monograph genre. It is observed to what extent these elements help the writer to position himself argumentatively. To carry out this investigation, a monograph from the Human Sciences area, from the Social Communication course, is collected and a qualitative methodology is used, based on theoretical assumptions of Textual Linguistics. The analyzes reveal the execution of socio-rhetorical movements by the writer and that the argumentative operators were responsible for complying with the used argumentative sequences. Therefore, it appears that guiding undergraduate students about these mechanisms can provide them with strategies that corroborate to fulfill the argumentative content expected in the monograph genre.

Keywords: Monograph; Argumentation; Argumentative operators.

\section{Referências}

KOCH, I. G. V. Argumentação e linguagem. São Paulo: Cortez, 2011. .; ELIAS, V. M. Escrever e argumentar. São Paulo: Contexto, 2016. 240 p. 
MOTTA-ROTH, D.; HENDGES, G. R. Produção textual na universidade. São Paulo: Parábola, 2010.

RIBEIRO, J. A sequência argumentativa e as categorias de argumentos no

texto escolar nos níveis de ensino fundamental e médio. 2012. 197f. Tese (doutorado) - Universidade Federal do Paraná, Curso de Pós-graduação em Estudos Linguísticos, Curitiba, 2012.

SOUZA, C. R. R. de; SILVA, W. M. da. Gênero monografia em contexto de produção acadêmica escrita. Raído, Dourados, MS, v. 12, n. 27, jan./jun. 2017 - ISSN 1984-4018.

SWALES, J. M. Research genres: exploration and applications. Cambridge: Cambridge University Press, 2004. 